\title{
Tracking Student Performance Tool for Predicting Students EBPP in Online Courses
}

\author{
https://doi.org/10.3991/ijet.v16i23.25503 \\ Iman Al-Kindi $\left.{ }^{\bowtie}\right)$, Zuhoor Al-Khanjari \\ Sultan Qaboos University, Muscat, Sultanate of Oman \\ m109107@student.squ.edu.om
}

\begin{abstract}
Our motivation in this paper is to predict student Engagement (E), Behavior (B), Personality (P), and Performance (P) via designing a Tracking Student Performance Tool (TSPT) based on Moodle logfile of any selected courses. The proposed tool was develop using Python programming language along with Microsoft Excel packages for progressing data. The tool follows the predictive EBP model that focuses mainly on student's EBP and Performance. The instructor could use it to monitor the overall performance of their students during the course. The data used in this paper was a log file of the "Internet Search Strategies "course where 38 students were enrolled. The results of testing the tool show that the developed tool gives the same as manual results analysis. Analyzing Moodle log of any course using such a tool is supposed to help with the implementation of similar courses and helpful for the instructor in re-designing it in a way that is more beneficial to the students. This paper sheds light on the importance of studying student's EBP and Performance and provides interesting possibilities for improving student performance with a specific focus on designing online learning environments or contexts. This paper shows part of Ph.D. research in progress that aims to "propose a framework for smart learning behavior environment."
\end{abstract}

Keywords-EBP predictive model, SQU-SLMS framework, student engagement, student behavior, student personality, student performance, Moodle log

\section{$1 \quad$ Introduction}

Nobody can deny that education evolves, and technology plays a significant role in this evolution [1]. Many educational institutions starting from universities, colleges, and schools, rely on Modular Object-Oriented Dynamic Learning Environment (Moodle). Moodle is a content management system that divides information into courses and sections, including course materials, activities, and resources. In addition to face-toface studying, Sultan Qaboos University (SQU) employs Moodle in its teaching and learning process. Learning behavior will alter as technology advances, resulting in more extraordinary working environment skills [2]. Therefore, under such circumstances, there are critical needs to study such as student Engagement (E), Behavior (B), Personality (P), and performance to provide an intelligent learning behavior environment to meet the demands of students. 
Every day we extracted massive amounts of data from various sources, including social media, daily transactions, and medical information. We do not profit from the potentially beneficial information extracted from these data since they were kept as row data in databases [3]. New challenges are being identified as information and communication technologies improve, owing to the vast amounts of data regarding students' activities, academic outcomes, and user interactions being stored [4]. Studying these data could benefit both instructors and students and create new learning paths [5]. Moodle retains detailed logs of all events students participate in and what items they access [6]. As a result, it is vital to develop tools to help instructors track students' EBP and Performance. Overall, this paper proposed Tracking Student Performance Tool (TSPT) for instructors to potentially assist them proactively and effectively in developing additional content for low and average student performance. This tool is an intelligent instructor tool to analyze, visualize, and tracking their student Engagement, Behavior and Personality (EBP), and Performance. The proposed mechanism is developed as a prototype to support the proposed EBP model inside the Sultan Qaboos UniversitySmart Learning Management System (SQU-SLMS) framework achievement.

This study expands a previously published paper entitled: "Exploring Factors and Indicators for Measuring Students' Performance in Moodle Learning Environment." this paper presents an EBP model for predicting student performance in Moodle online courses based on their EBP and Performance. As its subject, the report used the log files of 38 students of the Internet Search course, which gave in Fall 2019. The result of the previous research was an empirical study focused on analyzing Moodle log files manually to check if we can consider students' EBP as indicators for students' performance. This paper complements the previous article where the developing TSPT can do the manual $\log$ file analysis.

This paper is organized as follows: the background section contains information on the predictive EBP Model and SQU-SLMS framework. The literature review section introduces some previous work about predicting student performance. The implementation section presents the technical aspects of the proposed tool. The validation section explains how the authors validate the proposed TSPT by a case study suggesting an application to predict students' performance in a selected course. The discussion section provides the main findings of the study. Finally, the paper provides the conclusions.

\section{Background}

\subsection{Moodle log file}

Moodle is a free learning management system that creates sophisticated, flexible, and engaging online courses [7]. One of the most challenging factors in Moodle could extract student engagement, behavior, personality, and performance from log file Moodle courses. Due to the nature of the design of Moodle, it can routinely collect activity data on students through its profiles' log files of the student. Due to the fundamental limitation in managing these extensive log information records produced by students, teachers cannot test them manually. The collected data display general information of 
student's engagement and behavior, such as student's personal information, number of accessing the course, duration of the visit of each item in the class. Moodle has generated a vast amount of data that can utilize to study the interactions of students. It keeps track of each student's activity, such as reading, writing, completing various tasks [8]. This data helps analyze student EBPP and determine whether trends contribute to enhanced learning outcomes [9].

\subsection{EBP predictive model}

The smart EBP predicting model collects students' EBP data from the log file kept in Moodle. The model then generates students' engagement, behavior, personality, and performance [10]. The instructor would re-prepare the course to provide tailored learning according to students' needs to improve mid and low performance [11]. This model frequently motivates instructors to engage students in various activities via LMSs (e.g., Moodle), allowing students to participate in online courses.

\subsection{SQU-SLMS framework}

This paper is considered part of the main Ph.D. study that proposes a Sultan Qaboos University- Smart Learning Management System "SQU-SLMS" framework for developing an intelligent learning environment. It uses an existing Learning Management System (i.e., Moodle), used at SQU. In addition, it uses a brilliant technical-predictive model, which is an incorporated component into SQU-SLMS. The mean of "smart" here is reusing the Moodle to study the log files of any selected course to explore that student's engagement, behavior, and personality could be considered indicators of student's performance [12].

One of the essential points is that the proposed framework makes students' EBPP in any selected course smart and effective. The student engagement process starts with the way students will interact with the instructor inside the Moodle environment. The purposes of proposing the framework for an intelligent learning environment are:

- To enhance the interaction between instructor and students.

- To develop an observed interaction process that could use in the Moodle environment to indicate patterns of interaction, such as students choosing their learning tasks and engagement, behavior, personality, and performance patterns.

- To focus more on how the instructor can benefit from a log file of the courses in Moodle to answer the student's needs.

\section{$3 \quad$ Literature review}

It is essential to scan the previous related works to check how others have contributed to predicting student performance, which is the primary purpose of this study. In this sense, multiple attempts ranged from either analyzed the log file or developed different tools that would assist in predicting student performance in online courses. 


\subsection{Predicting student performance using developed tools}

For example, to see if there was a link between LMS use and student performance. A Learning Analytics tool was built to retrieve data from the LMS logs of two courses. According to the study, discussion postings, peer contact, and exercises were significant contributors to students' academic progress in blended learning. Nonetheless, students' learning performance was shown to be unaffected by time spent in the LMS, the number of downloads made, or the frequency with which they logged in [13]. Meanwhile, Moodle Predicta was also proposed, which is a desktop tool for educational data mining. This tool was developed in Java and can be utilized within the Moodle system by non-technical users. Moodle Predicta was separate into two components: Moodle Predicta to visualize Moodle course data and predict student performance [14]. Besides, there was an attempt to develop an IT tool that offers students formative feedback to improve their performance in large-scale lectures. The findings demonstrated that using the IT tool could significantly improve objective and perceived student performance [15]. More in more, to investigate the feasibility of predicting a student's grade via using Moodle. The relationships between access to materials and the final step were examined to do this. These correlations could potentially be used to forecast a student's grades. As a result, a Petri nets model was developed to predict students' grades based on LMS use based on the highest correlation [16].

\subsection{Predicting student performance using different methods}

In addition, to use Data Mining techniques to examine student behavior in a blended learning program, especially procrastination behavior, concerning performance. The findings underscore the importance of time management in online learning settings, especially academic accomplishment, as there is a link between procrastination characteristics and student performance [17]. Second, to test the portability of models built from Moodle logs from 24 academic courses. The proposed method seeks to determine if the comparable grouping of studies based on the quantity of usage of activities provided by records impacts the portability of prediction models and whether utilizing numerical or categorical qualities affects the portability of prediction models. The findings reveal that it is only possible to transfer prediction models to new courses with adequate accuracy and portability [18]. Finally, to examine whether LMS data can predict student performance in classrooms when LMS is used to supplement face-to-face instruction. The study [19] demonstrated that student login activity could be used to predict academic performance. An additional study performed a correlation analysis to see how the educational activities of students in the Moodle system affected the final grade. The findings show that gender affiliation is related to overall performance but has no bearing on training material choices [20] to give lecturers criteria for categorizing student learning outcomes early on in the teaching process. Finally, the researcher created a solution to assess students' behavior from Moodle LMS data and forecast the average learning score at the end of the course using the Linear Regression technique [21]. 


\section{$4 \quad$ Research question}

As we mentioned earlier, this paper is an extension of the previously published article. Therefore, the researcher question set here will be the same as the research question in that paper. Which aim to find an answer to the question:

Can Student's Engagement, Behavior, and Personality be considered as indicators for Student's Performance? [22].

\section{Implementation}

The purpose of implementation is to align the proposed EBP predictive model as a sub-model inside the proposed SQU-SLMS framework with a real-life functional system or tool. This step is required to translate the architecture of the framework into a functional prototype. This transformation can be provided in any application, either as a complete system or tool or just a prototype as a proof of concept for the proposed solution.

The development of the Tracking Student Performance Tool is carried out using Python programming language and Microsoft Excel. These programs have been selected for implementation due to their features which cope with the functionalities of the EBP predictive model. Python is a high-level, general-purpose programming language that is interpreted. Python's programming philosophy prioritizes code readability, as shown by the extensive use of indentation. Its language constructs and object-oriented style aim to assist programmers in writing simple, logical code for both small and large-scale projects [23]. Microsoft Excel is a program that allows the creation of spreadsheets. Excel is a handy go-to program that is both understandable and familiar. A core feature of Excel is the ability to do ad hoc analysis [24]. It is a robust analysis of vast volumes of data that allows users to rapidly and efficiently narrow down the criteria that will help them make choices using powerful scraping, sorting, and search methods [25]. Python has a lot of packages and libraries to manipulate data. As the data was in the form of excel files, so the researcher used Python to read and import Excel files. Excel is used to store the data, but the manipulation and results are directly stored and visualized in the tool.

\subsection{Workflow of the proposed tool}

Fig.1 illustrates the workflow of TSPT, which consists of four main processes along with the exact steps needed to complete a process, which are Sign Up, Login, Add Course, and Display Course. In each cycle, specific sub-processes need to be taken to achieve the primary process's goal. The implementation section discusses in detail the work of each process in the proposed tool. 


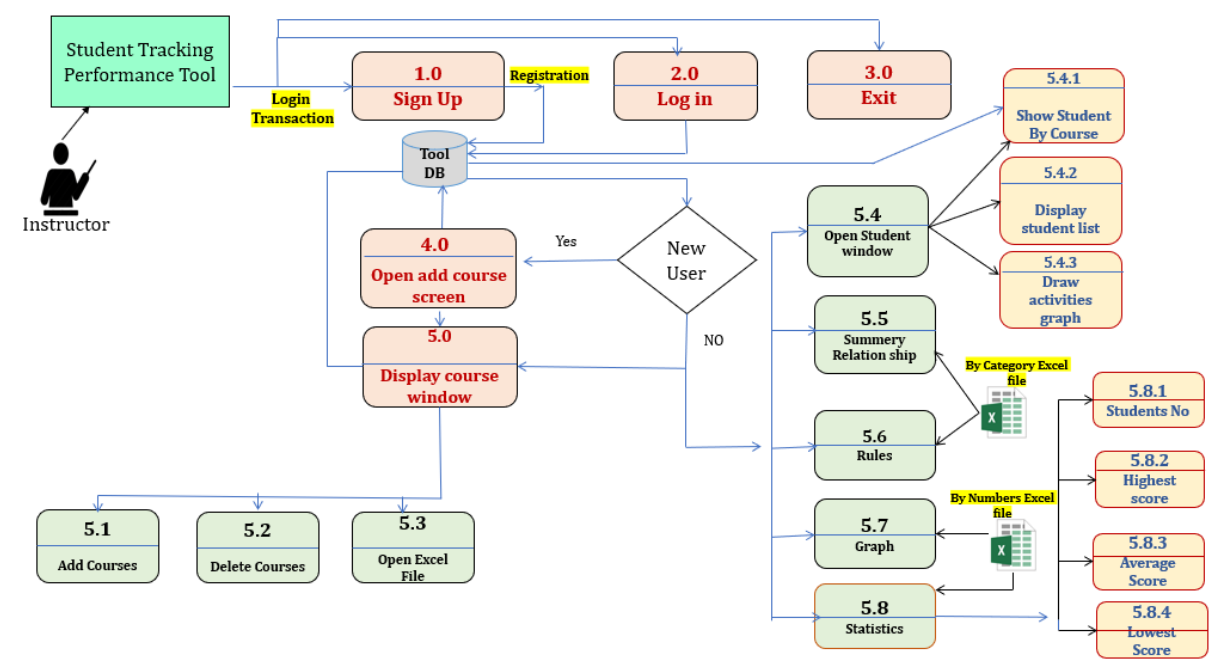

Fig. 1. Workflow of the Proposed TSPT

\subsection{Validation of TSPT}

To validate the proposed TSPT, the researcher compares the results obtained from manual analysis and the results extracted from the tool to check if the tool gives us the same results. Hence, we can recommend this tool for instructors to start using it. Therefore, in this section, the authors compare all results from the three case studies conducted and use the same logfiles data by uploading them into the tool for each course separately and then check the results.

The data extracted from the "Internet Search Strategies" logfile was used to test the proposed tool. In addition, complete results of the manual analysis of this course were published in [22]. Therefore, in this paper, the authors will compare the manual and tool results only.

The data distribution for performance and EBP factor. Fig. 2 illustrates the results of students Performance and EBP factors based on the manual process. 


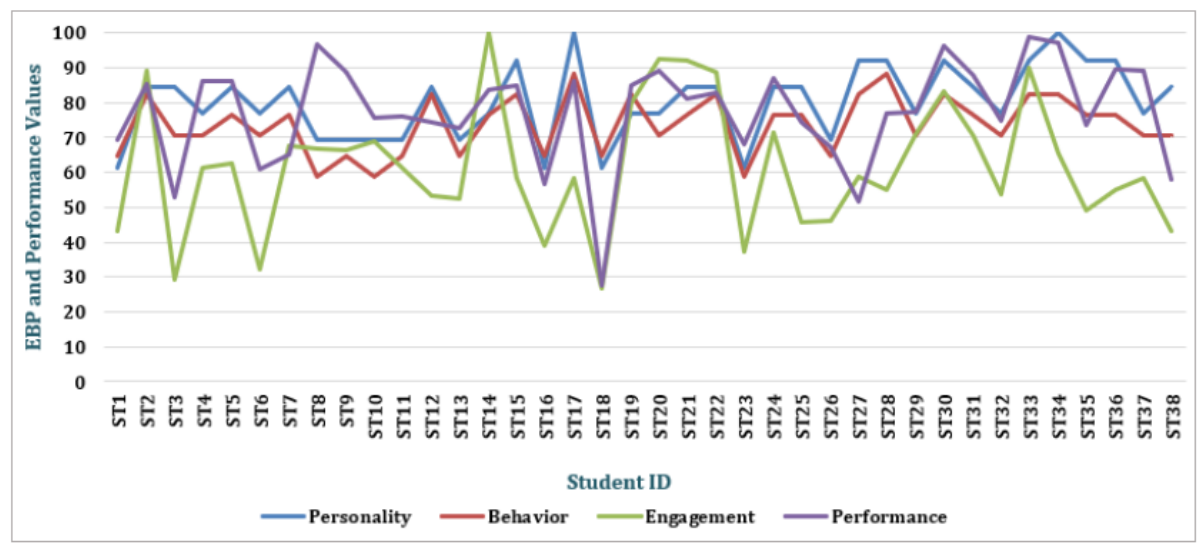

Fig. 2. Result of student data Performance and EBP factors (MANUALLY)

Based on the tool using the same course data, the overall distribution is illustrated in Fig.3.

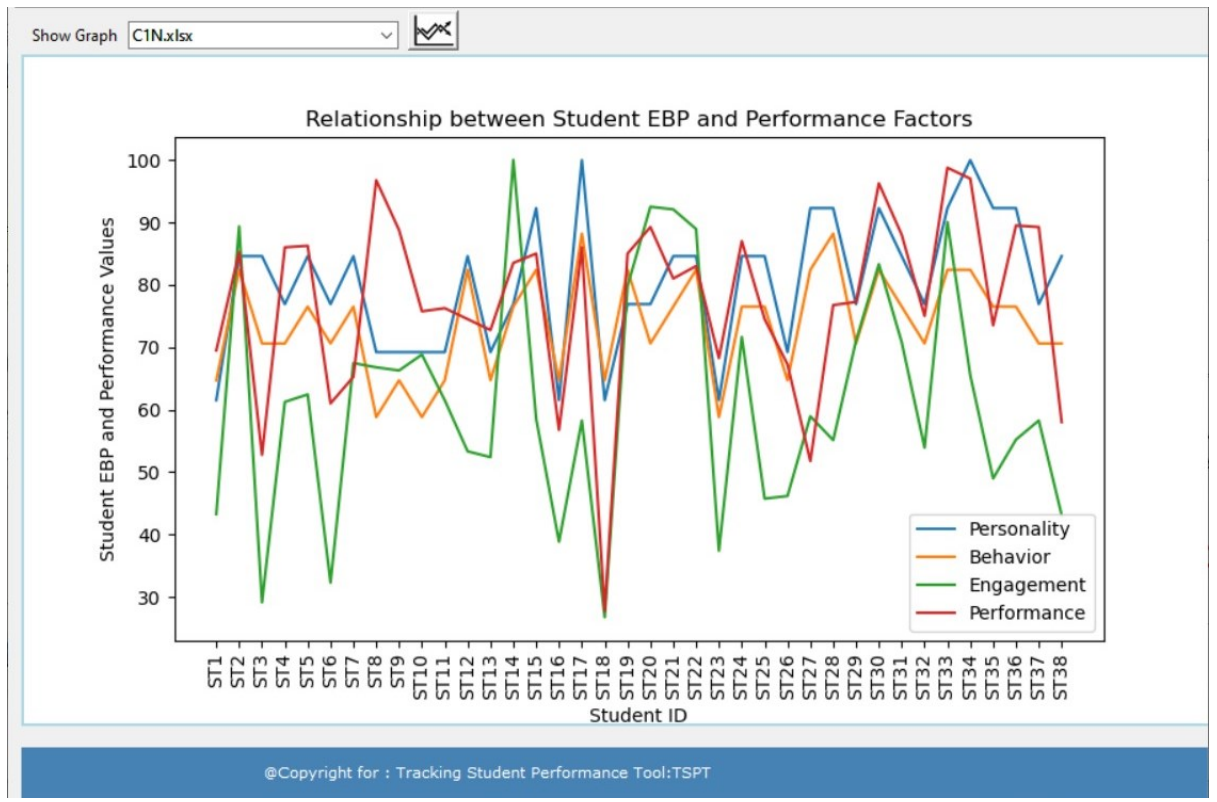

Fig. 3. Result of student data Performance and EBP factors (Tool)

By comparing the curves, they are identical. This means the tool gives accurate results in this part of the process.

Summary of relationships between engagement and behavior. Based on Table 1 and Fig.4, the developed tool gives the same manual results. 
Table 1. Summary of relationships between Engagement and Behavior

\begin{tabular}{|l|c|c|c|}
\hline \multicolumn{1}{|c|}{ E / B } & LE & AE & HE \\
\hline $\mathrm{LB}$ & 0 & 0 & 0 \\
\hline $\mathrm{AB}$ & 3 & 14 & 1 \\
\hline $\mathrm{HB}$ & 0 & 13 & 7 \\
\hline
\end{tabular}

(a) Manual Results

\begin{tabular}{|c|c|c|c|}
\hline \multicolumn{2}{|c|}{ Engagement/Behavior } & & \\
\hline E/B & LE & AE & HE \\
\hline LB & 0 & 0 & 0 \\
\hline AB & 3 & 14 & 1 \\
\hline HB & 0 & 13 & 7 \\
\hline
\end{tabular}

(b) Tool Results

Fig. 4. The summary relationships between Engagement and Behavior using the tool and manually

Summary of relationships between behavior and personality. Based on Table 2 and Fig.5, the developed tool gives the same manual results.

Table 2. Overview of relationships between Behavior and Personality

\begin{tabular}{|l|c|c|c|}
\hline B/ Pers & LB & AB & HB \\
\hline LPers & 0 & 0 & 0 \\
\hline APers & 0 & 10 & 0 \\
\hline HPers & 0 & 8 & 20 \\
\hline
\end{tabular}

(a) Manual Results

\begin{tabular}{|c|c|c|c|}
\hline \multicolumn{2}{|c|}{ Behavior/Personality } & \multirow[b]{2}{*}{$\mathrm{AB}$} & \multirow[b]{2}{*}{$\mathrm{HB}$} \\
\hline B/Pres & LB & & \\
\hline LPers & 0 & 0 & 0 \\
\hline APers & 0 & 10 & 0 \\
\hline HPers & 0 & 8 & 20 \\
\hline
\end{tabular}

(b) Tool Results

Fig. 5. The summary relationships between Behavior and Personality using the tool and manually 
Summary of Relationships between Personality and Engagement. Based on Table 3 and Fig.6, the developed tool gives the same manual results.

Table 3. Overview of relationships between Personality and Engagement

\begin{tabular}{|l|c|c|c|}
\hline E/ Pers & LE & AE & HE \\
\hline LPers & 0 & 0 & 0 \\
\hline APers & 1 & 9 & 0 \\
\hline HPers & 2 & 18 & 8 \\
\hline
\end{tabular}

(a) Manual Results

\begin{tabular}{|c|c|c|c|}
\hline \multicolumn{2}{|c|}{ Engagement/Personality } & & \\
\hline E/Pers & LE & AE & HE \\
\hline LPers & 0 & 0 & 0 \\
\hline APers & 1 & 9 & 0 \\
\hline HPers & 2 & 18 & 8 \\
\hline
\end{tabular}

(b) Tool Results

Fig. 6. The summary relationships between Personality and Engagement using the tool and manually

Summary of Relationships between all factors with performance. Based on Table 4 and Fig.7, the developed tool gives the same manual results.

Table 4. Summary of relationships between the three factors

\begin{tabular}{|l|c|c|c|c|c|c|c|c|}
\hline $\begin{array}{c}\text { B \& E } \\
\text { \&Pers/ P }\end{array}$ & $\begin{array}{c}\text { HB, HE, } \\
\text { HPers }\end{array}$ & $\begin{array}{c}\text { AB, AE, } \\
\text { APers }\end{array}$ & $\begin{array}{c}\text { AB, AE, } \\
\text { HPers }\end{array}$ & $\begin{array}{c}\text { HB, AE, } \\
\text { HPers }\end{array}$ & $\begin{array}{c}\text { AB, LE, } \\
\text { HPers }\end{array}$ & $\begin{array}{c}\text { AB, HE, } \\
\text { HPers }\end{array}$ & $\begin{array}{c}\text { AB, HE, } \\
\text { APers }\end{array}$ & $\begin{array}{c}\text { AB, LE, } \\
\text { APers }\end{array}$ \\
\hline LP & 0 & 0 & 0 & 0 & 0 & 0 & 0 & 1 \\
\hline AP & 0 & 5 & 2 & 5 & 2 & 0 & 0 & 0 \\
\hline HP & 7 & 4 & 3 & 8 & 0 & 1 & 1 & 0 \\
\hline
\end{tabular}

(a) Manual Results

\begin{tabular}{|c|c|c|c|c|c|c|c|c|}
\hline & APers, & APers, & HPers, & HPers, & HPers, & HPers, & HPers, & HPers, \\
\hline P/Pers, B,E & AB,AE & AB, LE & HB, HE & AB,LE & AB,HE & HB,LE & HB, AE & AB,AE \\
\hline LP & 0 & 1 & 0 & 0 & 0 & 0 & 0 & 0 \\
\hline AP & 5 & 0 & 0 & 2 & 0 & 0 & 5 & 2 \\
\hline HP & 4 & 0 & 7 & 0 & 1 & 0 & 8 & 3 \\
\hline
\end{tabular}

(b) Tool Results

Fig. 7. The summary relationships between all factors and performance using the tool and manually 
The Results of Rules. Based on Fig. 8, the extracted rules are very similar to the derived rules manually, except the manual rules are shorter.

- If $[($ Behavior $=$ High $)$ AND $($ Personality $=$ High $)$ AND (Engagement $=$ High $)$

- Then (Performance $=$ High)

- If [(Behavior $=$ Average OR High) AND $($ Personality $=$ Average OR High) AND (Engagement $=$ Average) $]$ - Then (Performance $=$ High OR Average)

If $[($ Behavior $=$ Average $)$ AND $($ Personality $=$ High $)$ AND $($ Engagement $=$ Low $)]$

- Then (Performance $=$ Average $)$

- If $[($ Behavior $=$ Average $)$ AND $($ Personality $=$ Average $)$ AND $($ Engagement $=$ Low $)]$

- Then (Performance $=$ Low)

- If $[($ Behavior $=$ Average $)$ AND $($ Personality $=$ High OR Average $)$ AND [(Engagement $=$ High $)]$

- Then (Performance $=$ High)

(a) Manual Results

\begin{tabular}{|c|c|c|c|c|}
\hline If (Pers=Average And Behavior=Average And Engagement=Average) Then & & Averas & & High \\
\hline If $($ Pers $=$ Average And Average=High And Engagement $=$ Low $)$ Then $(P=$ & Low & & & \\
\hline If (Pers=High And = Behavior=High And Engagement=High) Then $(\mathrm{P}=$ & & & High & \\
\hline If (Pers=High And Behavior=Average And Engagement=Low) Then $(P=$ & & Average & & \\
\hline If (Pers=High And Behavior=Average And Engagement=High) Then $(\mathrm{P}=$ & & & High & \\
\hline If (Pers=High And Behavior=High And Engagement=Average) Then $(\mathrm{P}=$ & & Average & High & \\
\hline If (Pers=High And Behavior=Average And Engagement=Average) Then ( $P=$ & & Average & High & \\
\hline
\end{tabular}

(b) Tool Results

Fig. 8. The summary rules of the case study using the tool and manually

\subsection{Access the tool}

The tool will be shared with the instructors via email as a link. Where the instructors in both cases can click the link, then the tool folder will be downloaded on their PC, and the instructor may start to use the tool.

\section{Discussion}

Some of the studies implemented the tools to predict students' grades. While, the proposed mechanism in this paper focused on student engagement, behavior, personality, and performance. Moreover, TSPT offers a summary relationship of the factors mentioned above of students and then simplifies those relationships in terms of if-then rules. Further, the tool provides a complete analysis of each student in a specific course. Thus, the instructor can easily track their students.

Regarding the new knowledge added in E-learning, online courses, and educational environment, such analysis can open the doors for more researchers to analyze the Moodle log file of any methods deeply. Additionally, the instructor can look at the overall approach (e.g., No of students enroll in the study, the average grade for each factor). In 
addition, following students' engagement, behavior, personality, and performance would provide personalized learning materials based on their requirements.

\section{Conclusion and future work}

Universities have adopted novel teaching and learning methods as a result of recent technological advancements [26]. This paper proposed and demonstrated a tool to predict students' performance in any Moodle online courses based on the log file of the selected period. The proposed mechanism has been developed based on the previously proposed predictive EBP model [11], which tracking how students engage and be-have in any course. The main objective was to enhance student performance by enabling instructors to use such a tool that helps identify students with average and low performance, thus allowing instructors to assist them through provide personalized learning materials depend on their preferences.

One experiment was conducted to check the validity of the proposed TSPT. It used a log file of the "Internet Search Strategies" course and the student's grades in all course assessments. The results showed that the proposed tool gives the same results as the manual analysis of the log file for the same course. Also, the finding from the proposed mechanism confirmed a relationship between EBP and Performance factors. Consequently, we can consider that students EBP as an indicator of students' performance. Therefore, instructors must accept new technology, monitor it continuously, and positively use it in teaching and learning [27-28]. Cause it is a standalone .exe tool. The proposed mechanism has been thoroughly inspected and can now be tested in an authentic learning environment by the instructors and start using it. One of the limitations of the proposed tool is that it needs to install on every PC to be able for each instructor to use it. On the other hand, there is a trend to integrate the tool into Moodle as a plugin tool. Considering the new educational settings due to the COVID 19 pandemic and the necessity of eLearning [29-30], we believe that the tool presented in this study will be a valuable learning tool shortly.

\section{Acknowledgment}

The authors wish to thank Sultan Qaboos University, College of Science, and the Department of Computer Science. This work is under Prof. Zuhoor Al-Khanjari's provision supported as a part of a scholarship of Doctoral Program from the Sultan Qaboos University.

\section{References}

[1] Ulfa, S., \& Fatawi, I. (2021). Predicting Factors That Influence Students' Learning Outcomes Using Learning Analytics in Online Learning Environment. International Journal of Emerging Technologies in Learning (iJET), 16(1), 4-17. https://doi.org/10.3991/ijet. v16i01. $\underline{16325}$ 
[2] Freigang, S., Schlenker, L., \& Köhler, T. (2018). A conceptual framework for designing smart learning environments. Smart Learning Environments, 5(1), 27. https://doi.org/10. $\underline{1186 / \mathrm{s} 40561-018-0076-8}$

[3] Badr, G., Algobail, A., Almutairi, H., \& Almutery, M. (2016). Predicting students' performance in university courses: a case study and tool in KSU mathematics department. Procedia Computer Science, 82, 80-89. https://doi.org/10.1016/j.procs.2016.04.012

[4] Félix, I. M., Ambrósio, A. P., Neves, P. S., Siqueira, J., \& Brancher, J. D. (2017). Moodle Predicta: A Data Mining Tool for Student Follow Up. In CSEDU (1) (pp. 339-346). https://doi.org/10.5220/0006318403390346

[5] Danubianu, M. (2015). A data preprocessing framework for students' outcome prediction by data mining techniques. In 2015 19th International Conference on System Theory, Control and Computing (ICSTCC) (pp. 836-841). IEEE. https://doi.org/10.1109/icstcc.2015. $\underline{7321398}$

[6] López-Zambrano, J., Lara, J. A., \& Romero, C. (2020). Towards portability of models for predicting students' final performance in university courses starting from Moodle Logs. Applied Sciences, 10(1), 354. https://doi.org/10.3390/app10010354

[7] Papadakis, S., Kalogiannakis, M., Sifaki, E., \& Vidakis, N. (2018). Evaluating Moodle use via Smart Mobile Phones. A case study in a Greek University. EAI Endorsed Transactions on Creative Technologies, 5(16). https://eudl.eu/doi/10.4108/eai.10-4-2018.156382

[8] Mostow, J., \& Beck, J. (2006). Some useful tactics to modify, map and mine data from intelligent tutors. Natural Language Engineering, 12(2), 195-208. https://doi.org/10. 1017/S1351324906004153

[9] Al-Kindi, I., \& Al-Khanjari, Z. (2020). A Novel Architecture of SQU SMART LMS: The New Horizon for SMART City in Oman. In 2020 Third International Conference on Smart Systems and Inventive Technology (ICSSIT) (pp. 751-756). IEEE. https://doi.org/10. $1109 /$ icssit48917.2020.9214141

[10] Al-Khanjari, Z., \& Al-Kindi, I. (2020). Proposing the EBP Smart Predictive Model Towards Smart Learning Environment. Journal of Talent Development and Excellence, 12(2s), 24222438. https://iratde.com/index.php/jtde/article/view/959

[11] Al-Kindi, I., Al-Khanjari, Z., \& Al-Salmi, J. (2020). Managing the Triangular Bond of the EBP for SQU Students Through the Proposed Test Model. International Journal of Engineering and Advanced Technology (IJEAT).ISSN: 2249-8958, Volume-10 Issue-1, October 2020. https://doi.org/10.35940/ijeat.A1914.1010120

[12] Al-Khanjari, Z., \& Al-Kindi, I. (2021). Proposing A Systematic Framework for SQU-Smart Learning Management System (SQU-SLMS). International Journal of Computing and Digital Systems, 10, 1-13. http://137.117.138.59/handle/123456789/4144

[13] Mwalumbwe, I., \& Mtebe, J. S. (2017). Using learning analytics to predict students' performance in Moodle learning management system: A case of Mbeya University of Science and Technology. The Electronic Journal of Information Systems in Developing Countries, 79(1), 1-13. https://doi.org/10.1002/j.1681-4835.2017.tb00577.x

[14] Félix, I. M., Ambrósio, A. P., Neves, P. S., Siqueira, J., \& Brancher, J. D. (2017). Moodle Predicta: A Data Mining Tool for Student Follow Up. In CSEDU (1) (pp. 339-346). https://doi.org/10.5220/0006318403390346

[15] Rietsche, R., Duss, K., Persch, J. M., \& Söllner, M. (2018). Design and Evaluation of an ITbased Formative Feedback Tool to Foster Student Performance. 39th International Conference on Information Systems (ICIS). https://www.alexandria.unisg.ch/publications/254982

[16] Balogh, Z., \& Kuchárik, M. (2019). Predicting student grades based on their usage of LMS moodle using Petri nets. Applied Sciences, 9(20), 4211. https://doi.org/10.3390/app9204211 
[17] Cerezo, R., Esteban, M., Sánchez-Santillán, M., \& Núñez, J. C. (2017). Procrastinating behavior in computer-based learning environments to predict performance: A case study in Moodle. Frontiers in psychology, 8, 1403. https://doi.org/10.3389/fpsyg.2017.01403

[18] López-Zambrano, J., Lara, J. A., \& Romero, C. (2020). Towards portability of models for predicting students' final performance in university courses starting from Moodle Logs. Applied Sciences, 10(1), 354. https://doi.org/10.3390/app10010354

[19] Mozahem, N. A. (2020). Using learning management system activity data to predict student performance in face-to-face courses. International Journal of Mobile and Blended Learning (IJMBL), 12(3), 20-31. https://doi.org/10.4018/ijmbl.2020070102

[20] Zhang, Y., Ghandour, A., \& Shestak, V. (2020). Using Learning Analytics to Predict Students Performance in Moodle LMS. International Journal of Emerging Technologies in Learning (iJET), 15(20), 102-115. https://doi.org/10.3991/ijet.v15i20.15915

[21] Thi-Diem Nguyen, A. (2021). Using Machine Learning to Predict the Low Grade Risk for Students based on Log File in Moodle Learning Management System. International Journal Of Computing and Digital System. http://journal.uob.edu.bh/bitstream/handle/123456789/ 4496/1570734064.pdf? sequence $=1$ \&isAllowed $=y$

[22] Al-Kindi, I., \& Al-Khanjari, Z. (2021). Exploring Factors and Indicators for Measuring Students' Performance in Moodle Learning Environment. International Journal of Emerging Technologies in Learning (iJET). Vol. 16, No. 12. (pp. 169-184). https://doi.org/10.3991/ ijet.v16i12.22049

[23] Wikipedia. (n.d). Retrieved from: https://en.wikipedia.org/wiki/Python_(programming_language). Retrieved on: 29/3/2021

[24] Feldman, Jess. (2021). How to Use Microsoft Excel Like a Data Analyst. Retrieved from: https://www.coursereport.com/blog/how-to-use-microsoft-excel-like-a-data-analyst. Retrie ved on: 29/3/2021

[25] Cook, Simon. (2021). Advantages of Microsoft Excel. Retrieved from: https://turbofuture.com/computers/Advantages-of-Microsoft-Excel. Retrieved on: 29/3/2021

[26] Papadakis, S., Kalogiannakis, M., Sifaki, E., \& Vidakis, N. (2017). Access moodle using smart mobile phones. A case study in a Greek University. In Interactivity, game creation, design, learning, and innovation (pp. 376-385). Springer, Cham. https://doi.org/10. 1007/978-3-319-76908-0 36

[27] Poultsakis, S., Papadakis, S., Kalogiannakis, M., \& Psycharis, S. (2021). The management of Digital Learning Objects of Natural Sciences and Digital Experiment Simulation Tools by teachers. Advances in Mobile Learning Educational Research, 1(2), 58-71. https:// doi.org/10.25082/amler.2021.02.002

[28] Shoraevna, Z., Eleupanovna, Z., Tashkenbaevna, S., Zulkarnayeva, Z., Anatolevna, L., \& Nurlanbekovna, U. (2021). Teachers' Views on the Use of Information and Communication Technologies (ICT) in Education Environments. International Journal of Emerging Technologies in Learning (iJET), 16(3), 261-273. https://doi.org/10.3991/ijet.v16i03.18801

[29] Karakose T, Yirci R, Papadakis S. Exploring the Interrelationship between COVID-19 Phobia, Work-Family Conflict, Family-Work Conflict, and Life Satisfaction among School Administrators for Advancing Sustainable Management. Sustainability. 2021; 13(15):8654. https://doi.org/10.3390/su13158654

[30] Karakose, T.; Yirci, R.; Papadakis, S.; Ozdemir, T.Y.; Demirkol, M.; Polat, H. Science Mapping of the Global Knowledge Base on Management, Leadership, and Administration Related to COVID-19 for Promoting the Sustainability of Scientific Research. Sustainability 2021, 13, 9631. https://doi.org/10.3390/su13179631 


\section{Authors}

Iman Al-Kindi is currently a Ph.D. candidate in the Department of Computer Science, College of Science at Sultan Qaboos University, Sultanate of Oman. She received her BSc in software Engineering from Higher College of Technology, Sultanate of Oman, and MSc in Computer Science from Sultan Qaboos University, Sultanate of Oman. In addition, she has worked as a visiting lecturer for more than one year at Sultan Qaboos University, Sultanate of Oman.

Zuhoor Al-Khanjari is a professor in software engineering. She worked as the HOD of the Department of Computer Science, College of Science at Sultan Qaboos University, Sultanate of Oman. She received her BSc in mathematics and computing from Sultan Qaboos University, Sultanate of Oman, MSc, and Ph.D. in computer science (software engineering) from Liverpool, UK. Her research interests include software engineering, software testing techniques, database management, e-learning, $\mathrm{m}$ learning, and mobile computing. Currently, she is the coordinator of the software engineering group in the Department of Computer Science, Sultan Qaboos University, Sultanate of Oman. Also, she is coordinating e-learning facilities in the same department. She is a member of the International Arab Journal of Information Technology (IAJIT) editorial board and the International Arab Conference on Information Technology (ACIT) executive committee.

Article submitted 2021-07-15. Resubmitted 2021-09-26. Final acceptance 2021-10-02. Final version published as submitted by the authors. 


\section{Appendix- Technical Aspects}

In this section, the authors shed light in detail on the work of the proposed TSPT.

\subsection{Main Interface Form}

In the main interface form, as shown in Fig.9, the instructors are supposed to be able to choose between three main functions, which are:

- Sign Up: if the instructor uses the tool for the first time, they need to log in to the instrument.

- Login: After signing up, the instructor can log in to the tool using their user ID and password

- Exit: To exit.

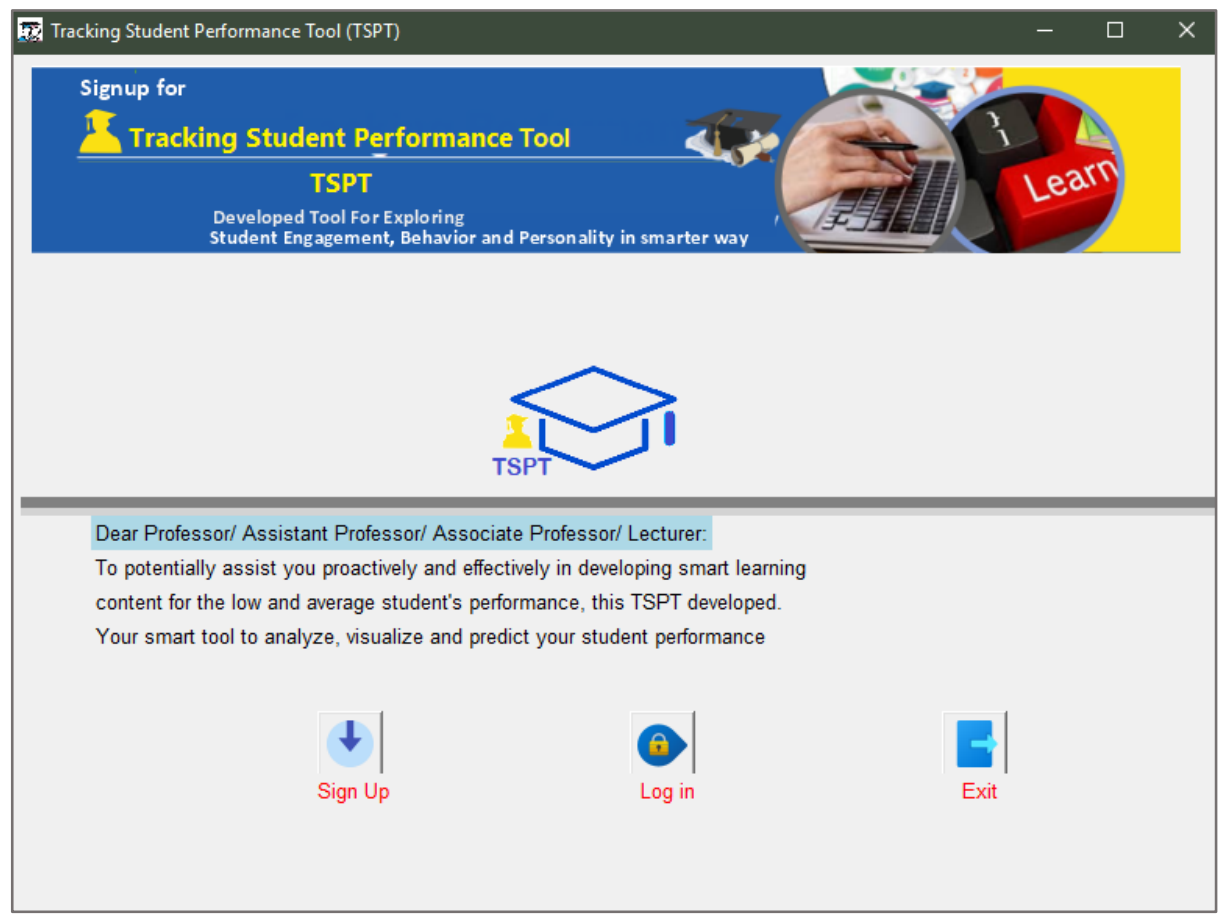

Fig. 9. Main Interface of TSPT

Sign Up Form. The instructor will have to sign up, registering their data.

Login Form. After singing, the instructor can log in to the tool using their user ID and password. For forgotten passwords, the instructor can write usernames and press the failed password button to receive an email on their email containing the password. Further, there are multiple forms available in the tool with different functions for each. 


\subsection{Excel Files Entry Form}

If the instructor is a new user, they will be direct to add a course screen to add their course files. Each course may contain two forms of files, one by number while the second with categories, as displayed in Fig.10. Each file must be in Excel format and stored in the tool directory next to the .exe file TSPT.exe.

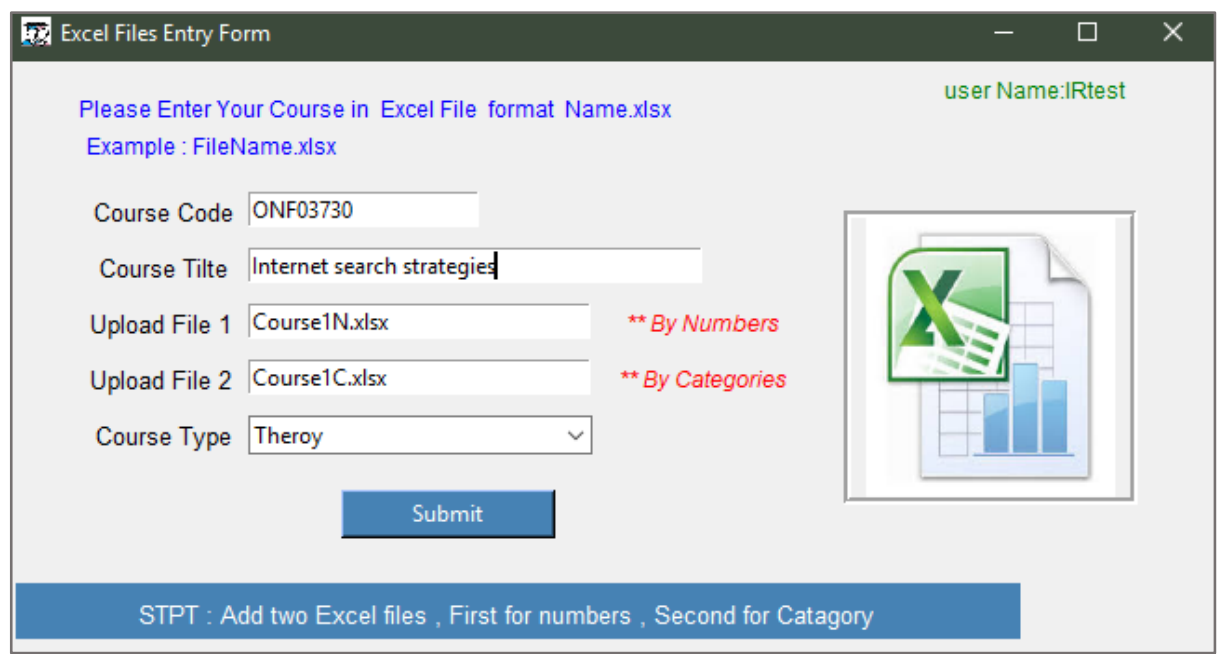

Fig. 10.Excel Files Entry Form of TSPT

\subsection{Courses Form}

The instructor will see excel files of their course displayed in the Combo box. Also, they may add a new study with excel files using the ADD button. The add file screen will be displayed to add excel files of the new course, as shown in Fig.11. In addition, the instructor may press the Refresh button to ensure that their new system is included in the combo box. Furthermore, if they select one file from the combo box, they should press to open the Excel file directly. 


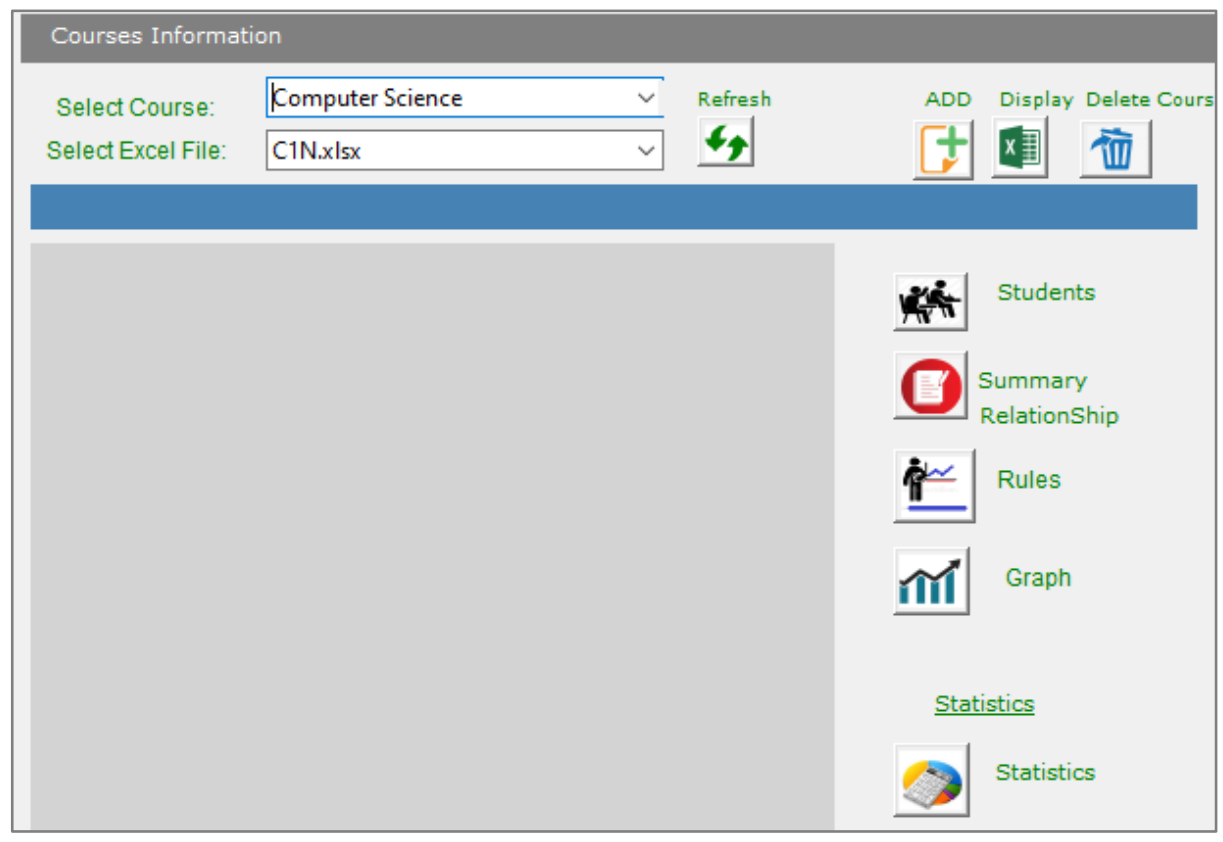

Fig. 11.Courses Form of TSPT

\subsection{Student Form}

Suppose the instructor presses the student's icon on the right side of the course form. They will be able to see the list of students. In addition, they can select any student, then click on the student ID to see the graph of student activities, Engagement, Behavior, Personality, Performance.

\subsection{Summary Relationship Form}

A list of those Excel files, with categories reading, will appear in the combo box only to select the one to display a count of the occurrence.

Where:

- E letter stands for engagement

- B letter stands for behavior

- Pers stands for personality

- Perf stands for performance

And

- L stands for Low

- H stands for High

- A stand for average 


\subsection{Graph Form}

A-Line graph between all factors plots a relationship between EBP and Performance factors in a specific selected course file from the combo box.

\subsection{Statistics Form}

The instructor may wish to browse student's max score in one course, Min, Average, count the number of students in one subject, and the number of activities. Statistics form will take the instructor for those statistics. It will display a survey of necessary statistics from the excel data number sheet, as shown in Fig.12.

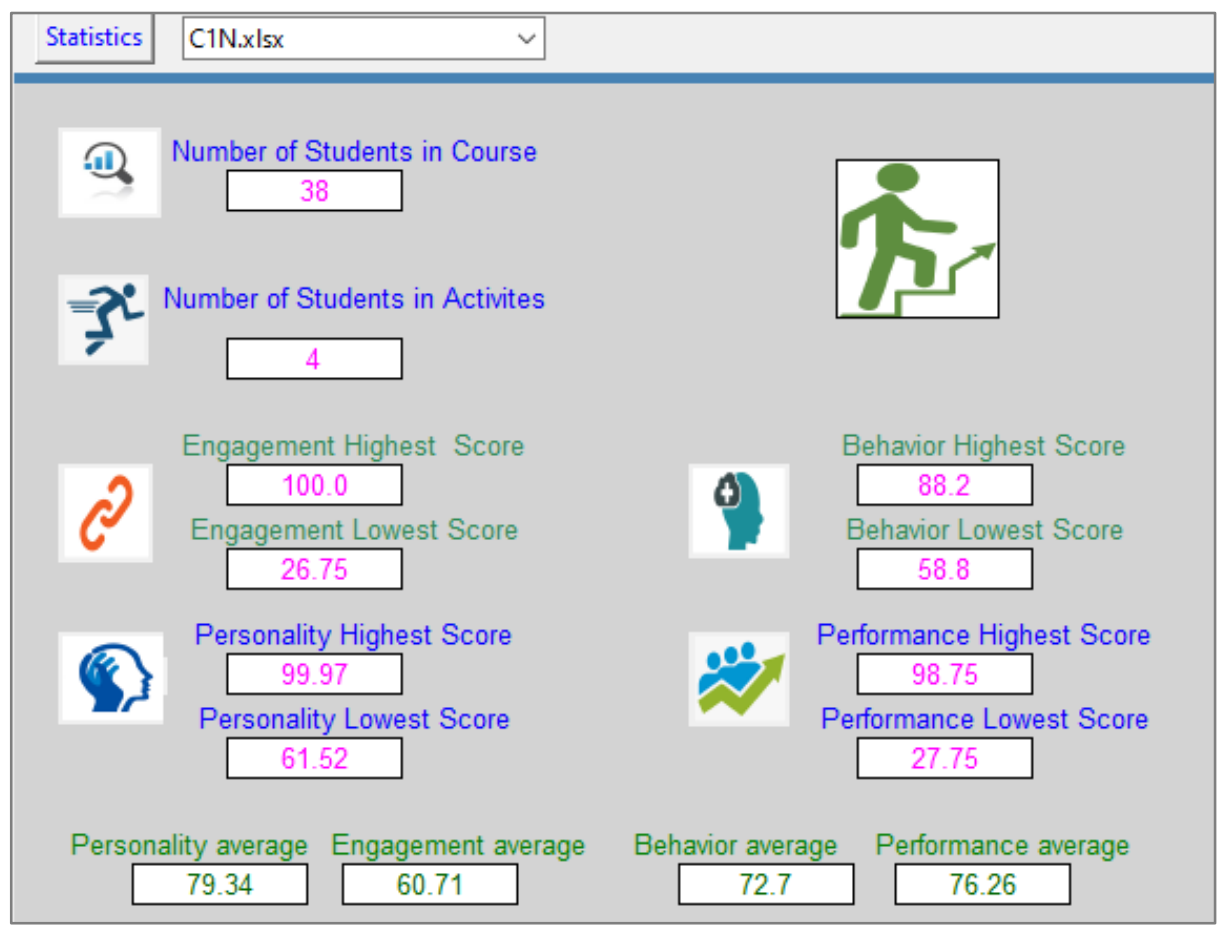

Fig. 12. Statistics Form 